\title{
Nutritional Status, Dietary Practices and Nutrition Related Beliefs of High School Girls in Urban Area of Bangalore City
}

\author{
Vipna Kumari Bhandari \\ Shri Swami Bhumanand College of Nursing Ranipur Jhal, Jwalapur, Haridwar
}

\begin{abstract}
The study was conducted to explore the nutritional status, dietary practices and nutrition related beliefs of high school girls' age between twelve to seventeen years. One hundred and fifty high school girls from two government schools of Bangalore were selected for the study by stratified random sampling. The research design was descriptive analytical and cross sectional. A semi-structural questionnaire was used to collect the data on dietary practices and nutrition related beliefs and observational checklist was used to collect on nutritional parameter. The finding revealed that $72.5 \%$ girls were malnourished out of which $69.2 \%$ were underweight and 3.3\% were overweight. Statistical analysis used was simple proportion and chi-square test which revealed that the majority $76.6 \%$ girls were found anemic. It may be due to the poor economic condition as the most of the girls' 78\% were belonged to the low and lower middle income families where their parents were partly skilled, unskilled and home-makers. Result shows that there was statistical association between nutritional status and statement of nutrition related beliefs that eating non-vegetarian food and green leafy vegetable improve the quality of blood. As a whole, the dietary practices of high school girls were inadequate. There is a dire need to educate the parents and teachers who must impart knowledge about nutrition related practices accurately.
\end{abstract}

Key words: Nutritional status, dietary practices, nutrition related beliefs, high school girls

\section{Introduction}

Adolescence girls are very importance section of our society as they are the potential mothers and homemakers in future. Moreover, they perform various other roles in the family and the community. It is a transitional period of dramatic physical growth and development. This period is marked by rapid and sequential physical and mental changes that transform a small child into a young adult girl.

These physical changes include increase in height, weight, deposition redistribution of fat etc. The physical changes that occur require the increased needs of nutrients like vitamins, protein and carbohydrates. Iron stores in the body before conception is major cause of the iron deficiency anemia during pregnancy. In endemic areas, the incidence of iodine deficiency disorder is high, resulting retardation. An undernourished girl has a risk for developing complications during pregnancy due to which the chances of her giving birth to a low birth weight infant increases, thus perpetuating a cycle of malnutrition and ill health.

According to WHO, about ${ }_{5}^{1 / \text { th }}$ of the world consist of adolescents, during this period good nutrition is very important for the growth and development. Inadequate nutrition during adolescence can have serious consequences throughout the reproductive years and beyond.

Under-nutrition in adolescent girls is a major public health problem in developing countries. Energy and nutrient needs are greater during adolescence than at any other time of life, except pregnancy and lactation. Today's adolescents are tomorrow's adults who are strength of the nation.

Malnutrition among the adolescent girls in the South East Asia has been an exceptionally large and complex problem. In the developing countries, the commonly used measures of nutritional problems include stunting which refers to being below the $5^{\text {th }}$ percentile of WHO height for age distribution, stunting was found to have a prevalence of 27 to 65 years in 9 out of 11 studies. Childhood under nutrition is highly prevalent in South Asia. ${ }^{1}$ Stunting in adolescence in $32 \%$ in India, $36 \%$ in Bangladesh and $47 \%$ in Nepal. ${ }^{2}$ Early adolescence after the first year of life is the second critical period of rapid physical growth and changes in body composition, physiology and endocrine. Rapid growth and changes heighten their nutritional requirements and risks of undernutrition. Parents simply need to provide more nutrients and emotional supports. ${ }^{3,4}$

In developing countries, factors associated with under-nutrition of adolescents are: poor household economic condition, periodic food shortage, burden of diseases, poor knowledge about long term consequences of under-nutrition of adolescents, quantity and quality of food, access of health and nutritional services. ${ }^{5}$

Dietary knowledge and access to resources are critical to improve health and nutrition in sustainable way. Adolescence is the time to learn and adopt healthy habits to avoid many health and nutritional problems later in life.

A rapid growth phase during adolescence needs special nutritional requirements because $20 \%$ growth happens in stature and 50\% growth happens in adult bone mass, hence, resulting in an increased requirement of 
nutrients like calcium. Additional $15 \%$ iron is required by an adolescent girl during her menstrual period to compensate the loss of blood. Anemia among the adolescent girls has been a major health hazards. They get stunted because of anemia and lack of protein energy.

According to WHO (2002) number of world's adolescent population, between 10 to 19 years of age, is 1200 million, and out of which $19 \%$ faces a series of nutritional challenges. Such nutritional challenges not only affect their growth and development but also their livelihood. Nevertheless, the adolescent population remains largely neglected, as they seem difficult to measure, and hard to reach, in which the need of adolescent girls in particular are often ignored.

There is paucity of literature both in western as well as in Indian setting regarding nutritional status, dietary practices and beliefs of the adolescents. Hence, they have become a targeted group receiving much attention.

Moreover, the assessment of nutritional status has been most essential for planning and providing the comprehensive care of the adolescent girls in recent years. Therefore, this study is needed for an understanding of nutritional status of adolescent girls and their dietary practices and beliefs. The objectives of the study were assess the nutritional status, dietary practices and compare the nutritional status and nutrition related beliefs of high school girls.

\section{Methodology}

A representative sample of 150 high school girls from VIII, IX and X standards was selected by the stratified random sampling technique from 2 government high schools, 75 students from each school and 25 students from each class, age between 12 to 17 years were selected. A research approach adopted for this study is descriptive and research design chosen is cress-sectional. The pre-tested tool used was clinical examination check list for nutritional status such as semi-structured questionnaire on dietary practices and closed-ended questionnaire on nutrition related beliefs. Clinical examination check list and filling up of questionnaire took 30 minutes. Clinical examination check list and information from the questionnaire was evaluated by using descriptive and inferential statistics that is mean, standard deviation, percentage for central tendency and dispersion of data and chi-square test was utilized to determine the difference between groups. Pilot study was conducted. The tool was tasted by test-retest method and found highly reliable, $r=0.92$. Tool was validated by nine experts of related field.

To assess the nutritional status, BMI was calculated and the body weight and height of subjects recorded. Height was measured in $\mathrm{cm}$ by marking on a wall of the school with the help of measuring tape. All girls were measured against the wall, and were asked to remove the footwear and stand on their heels together and head upright position so that the line of vision was perpendicular to the body. A glass scale was brought down to the topmost point of the head and recorded. For weight, a bathroom scale was used. It was calibrated against known weight regularly. Zero error was checked for and removed if present every day. Subjects were weighted with one set of cloths. Weight was recorded to the nearest $500 \mathrm{gm}$. Hemoglobin was checked by TALLQVIST, hemoglobin scale. Body mass index was calculated by weight $(\mathrm{kg}) / \mathrm{height}^{2}(\mathrm{~m})$.

\section{Results}

There were 150 high school girls between the age group of 12 to 17 years and $81 \%$ of them were 12 to 14 years and $69 \%$ of them were between 15 to 17 years. Their mean age was 14.31 years. Girls have had adults and children in their families, their mean and range are 3.07 and 2.93 respectively. About mean and percentage of the families' annual income was Rs. 30636 and 26\% and 52\% were belonged to lower and lower middle families. Majority $89 \%$ of girls were from Hindu family followed by Christian and Muslim 6\% and 5.3\% respectively.

Table -1 shows the distribution of high school girls according to education and occupation of parents. Regarding education of their fathers, $62.6 \%$ were having high school education, $25.3 \%$ were illiterate, and $12 \%$ were intermediate and graduate, whereas $40 \%, 37.9 \%$ and $21.9 \%$ illiterate, up-to the high school and graduate respectively. Concerning the weight and height of the girls, majority $46.66 \%$ were ranges from $31-40 \mathrm{~kg}$, and height ranges between $141-160 \mathrm{~cm}$. The mean and SD was 41.30, 7.21 and 152.09 and 6.46 .

Table-1 Distribution of high school girls according to education and occupation of parents

\begin{tabular}{|c|c|c|c|c|}
\hline \multirow[t]{2}{*}{ Characteristics } & \multicolumn{2}{|l|}{ Father } & \multicolumn{2}{|l|}{ Mother } \\
\hline & $\begin{array}{l}\text { frequen } \\
\text { cy }\end{array}$ & $\%$ & frequency & $\%$ \\
\hline \multicolumn{5}{|l|}{ Education } \\
\hline Illiterate & 38 & 25.3 & 60 & 40 \\
\hline Primary - & 15 & 10 & 28 & 18.6 \\
\hline Middle school 5-7 & 31 & 20.6 & 29 & 19.3 \\
\hline
\end{tabular}


Nutritional Status, Dietary Practices and Nutrition Related Beliefs of High School Girls in ...

\begin{tabular}{|l|l|l|l|l|}
\hline High school 8-10 & 15 & 10 & 29 & 19.3 \\
\hline Intermediate 11-12 & 48 & 32 & 4 & 2.6 \\
\hline Graduation \& above >12 & 15 & 10 & 0 & 0 \\
\hline \multicolumn{5}{|l|}{} \\
Occupation & 30 & 20 & 1 & 0.7 \\
\hline $\begin{array}{l}\text { Professional } \\
\text { Technician, Police, Writer, }\end{array}$ & 6 & 4 & 8 & 5.3 \\
\hline $\begin{array}{l}\text { Intermediate } \\
\text { Govt. Service, Business }\end{array}$ & 31 & 20.6 & 5 & 3.3 \\
\hline $\begin{array}{l}\text { Skilled } \\
\text { Tailor, Welder, Weaves supervisor }\end{array}$ & 30 & 20 & 11 & 7.3 \\
\hline $\begin{array}{l}\text { Party skilled } \\
\text { Factory worker, Mints, Plumber }\end{array}$ & 41 & 27.3 & 22 & 14.6 \\
\hline $\begin{array}{l}\text { Unskilled } \\
\text { Coolie, Flower seller, Helper Maid, } \\
\text { Supervisor }\end{array}$ & 0 & 0 & 103 & 68.6 \\
\hline Home maker, House wife & 12 & 8.0 & 0 & 0 \\
\hline Unemployed & & & \\
\hline
\end{tabular}

Table-1 revealed that education of the parents were $32 \%$ of father did only high school education and $40 \%$ mother were illiterate, $27 \%$ father were working as unskilled worker and $68.6 \%$ mother were home maker . Table- 2 presents $72.5 \%$ girls were malnourished out of which $69.2 \%$ were underweight and $3.3 \%$ were overweight.

Table-2 Distribution of high school girls based on their BMI

\begin{tabular}{|l|l|l|l|l|l|l|}
\hline Characteristics & BMI Measurements & Frequency & $\%$ & Mean & SD & Range \\
\hline Under weight & $<15-18.4$ & 104 & 69.2 & 17.75 & 2.66 & $12.38-28.63$ \\
Healthy & $18.5-24.9)$ & 41 & 27.3 & & & \\
Overweight & $25-29.9$ & 5 & 3.3 & & & \\
Obese & $>30$ & 0 & 0 & & & \\
& & & & & & \\
\hline
\end{tabular}

Table -3 reveals that majority $76.6 \%$ girls were anemic between the $10-12.49$ gm $\%$ and only $23.3 \%$ were healthy. Findings of clinical examination of the girls show that $59.3 \%$ were thin in built and $46.7 \%$ were pallor and $33 \%$ of them had bleeding gums and dental carries. About their food patterns $57.3 \%$ take green leafy vegetables once in a week and $77 \%$ respondents consuming 3 meals in a day and $21 \%$ had only 2 major meals. Girls numbering $80.66 \%$ do not take non-vegetarian food.

About the nutrition related practice of the high school girls $85.3 \%$ do not take breakfast and they skip it, $90.7 \%$ eat while watching TV.

Table-3 Hemoglobin levels of High School girls.

\begin{tabular}{|l|l|l|l|l|l|}
\hline $\mathrm{Hb}(\mathrm{gm} \%)$ & Frequency & $\%$ & Mean & SD & Range \\
\hline$<10.0-12.49$ (Anaemic) & 115 & 76.6 & 10.96 & 0.86 & $9.4-12.5$ \\
$12.5-18.0$ (Healthy) & 35 & 23.3 & & & \\
& & & & & \\
\hline
\end{tabular}

Table 3 revealed that majority of the $76.6 \%$ girls were anemic which are between $10-12.49$ gm\% and only 23.3 were healthy. Finding of clinical examination of the High School girls shows that 59.3\% were thin in built and $46.7 \%$ were pallor and $33.0 \%$ girls had bleeding gums and dental caries. About food patterns of the girls' $57.3 \%$ girls take green leafy vegetables once a week and $18 \%$ girls do not take non vegetarian food. About the nutrition related practice of high school girls $85.3 \%$ do not take breakfast and they skip this and $90.7 \%$ girls eat while watching TV.

Comparison of nutritional status and Nutrition Rerated practices of High School girls seems to show the results that girls those who have habit of watching TV while eating shown to be non significant, it may be very little amount of food or snacks may be eaten by many girls.

Nutrition related beliefs of high school girls which show that majority of $62 \%$ girls believe that obesity is generally due to intake of more food than required and $66 \%$ girls believe that energy is not required by the body during sleep and $62 \%$ girls believe that milk and milk product makes your bone and teeth strong. $75.5 \%$ girls believe that overheating meat and egg leads hardening and reduces digestion. It is also seen that there is no association between the nutritional status expressed in terms of malnutrition and healthy and nutrition related beliefs of high school girls. The statement eating non vegetarian food improve blood quality is significant.

Nutrition related beliefs of high school girls shows majority $62 \%$ that obesity is generally due to intake more food than required and also milk and milk product makes bones and teeth strong. $66 \%$ girls believe that energy is not required by body during sleep and $75.5 \%$ girls believe that over-heating meat and egg leads hardening of food and reduces digestion. 


\section{Discussion}

The present study results were compared with the data of similar studies done in Kohlapur, Maharastra ${ }^{6}$ found that adolescent girls belonging to lower and lower middle socio-economic status were $26.7 \%$ and $23.3 \%$. In present study, $78 \%$ girls were belonging to lower and lower middle socio-economic status.

According to the literacy level of the parents, $65.3 \%$ were illiterate as against $35 \%$ were literate. These findings are also similar to the study done in Kohlapur, Maharastra ${ }^{6}$ shows that for literacy level about parents were $73.3 \%$ and $26.7 \%$ mothers were illiterate and literate respectively. On the contrary, $60 \%$ fathers were literate. On the basis of occupation, only $31.34 \%$ of high school girls had mothers who were working outside the home whereas $68.66 \%$ of mothers of high school girls were homemakers.

The values of body weight $(\mathrm{kg})$ and height $(\mathrm{cm})$ of the high school girls were found to be markedly lesser than the standard value for the same age. The calculated values of BMI of $69.2 \%$ of high school girls were also found to be far below the standard values as given by ${ }^{7} \mathrm{WHO}$ for the same age of adolescent. .It is evident from the result that the adolescent girls were shorter and lighter as compared to average Indian girls. This is similar to the study done in Faridabad, Haryana ${ }^{8}$ found that $93.5 \%$ adolescents were below the BMI 18.5. These finding are similar to various other studies $2,6,9,10,11$ where they also found most of the girls were undernourished or below the BMI 18.5.

In present study $3.3 \%$ girl were overweight but no one was obese whereas study done in Delhi by ${ }^{12}$ found that $7.4 \%$ adolescent were obese. It may be due to their stable economic condition, amount, frequency and quality of food.

Anemia is an important nutritional problem among adolescent girls and in present study, it was found that $35 \%$ had normal HB levels as against $76 \%$ were anemic that is between $10.5-12.49$ gm\% as the HB level was checked by using “TALLQVIST HAEMOGLOBIN SCALE”. The mean hemoglobin was 10.96 gm\%. This is similar to other studies ${ }^{8,13,4,9}$ where majority of the girls were anemic. Also in Coimbatore, Ramdas and Sakir conducted a study on nutritional status of adolescent girls and food craving during menstruation studying 200 samples. They found that $20 \%$ subjects had anemia and $4 \%$ had dental caries. During the adolescence period, caloric and protein requirements are maximal. Increasing physical growth combined with poor eating habits contribute to the accentuating of the potential risk among the adolescents for poor nutrition.

In present study, the finding of clinical examination showed signs of possible nutrients and micronutrients deficiencies $59.3 \%$ girls were thinly built, $46.7 \%$ had pallor conjunctiva, $33.2 \%$ girls had bleeding gums and dental cassis. This is similar to study done by Tamang Shanta ${ }^{9}$ in Nepal. She found that $29 \%$ of participants had angular stomatitis and $7 \%$ participants had problem of bleeding gums. Other study done in Coimbatore $^{14}$ reveals similar findings where $18 \%$ had nail discoloration, $19 \%$ had cracked lip and $4 \%$ had dental carries. These may be due to low intake of iron, calcium and vitamin B complex and high intake of sweets like toffees, chocolates and poor hygienic practices.

In the present study, a majority $77 \%$ of high school girls had three major meals in a day even though about $85.4 \%$ girls skipped at least one meal in a day, in that half of the girls i.e. 50\% skipped only breakfast. Similar findings were also observed in Coimbatore ${ }^{14}$ where majorities $88 \%$ of the girls were consuming three meals per day. Other studies ${ }^{15,16}$ reveals that $96.8 \%$ girls consumed three major meals and $19.33 \%$ girls were non-vegetarian. On contrary, study done by Bhasin etal. ${ }^{17}$ found that $69 \%$ girls were non -vegetarian.

The present study also shows there was no statistically significant relationship between the type of meals, snacks and food taken with BMI of girls. This may be because of the poor quality and quantity of food taken by high school girls or lack of awareness of good nutrients food or because of low socio-economic background.

The present study shows that the high school girls had positive beliefs like $89.3 \%$ felt "adequate nutrition is essential for maintaining health and vision" and "Eating non-vegetarian food and green leafy vegetables improve blood quality" which shows that they had some positive beliefs that would help them to improve their nutritional status even though only one statement had significant relationship. This may be due to the gained knowledge by books and increased awareness though channels of mass media like TV, radio FM, magazines and internet. $67.7 \%$ girls believe that "Oily food should be avoided by those who are obese". It may be at this stage, girls are mare "figure" or beauty conscious and discussion with peer group may be other source of information in which they believe.

Among the negative belief, girls scored were $82 \%$ felt that "Green leafy vegetables provides less calories" and 63\% felt "Over heating meat and egg leads to hardening and reduces digestion". This study is similar to the study done by Srivastava et-al in Patna, Bihar ${ }^{16}$ where he found $82.4 \%$ girls believe that "Oil and ghee should be avoided by obese" and $88 \%$ believe that obesity is due to excess intake of calories than required. In present study, there was no association between nutritional status and nutrition related beliefs of high school girls .This may be due to lack of knowledge of the high school girls regarding nutrition and their relevance.

Health beliefs model by Rosenstoch's and Becker Maiman, which is used as conceptual framework helped the investigator to tailor the step of the research process to answer the research question, it is found that modifying factors like their religion, socio-economic variables, parents' education, occupation and income have 
influence on the dietary practices and beliefs of the high school girls and they are also influenced by the sources of information from magazines, friends and media exposure like TV, radio, internet, these all lead to likelihood of developing positive practices and beliefs in the high school girls.

It is well understood by the study that if modifying factors and sources of information is appropriate, then high school girls perceive and develop positive practices and belief better.In this study modifying factor and sources of information is lacking therefore dietary practices and beliefs of high school girls are poor.

Finding of the study reveals that there is no association between nutritional status and dietary practices of high school girls. It also reveals that regarding beliefs statements out of ten, only one statement has significant relationship. "Eating non-vegetarian food and green leafy vegetables improve blood quality". It may be due to poverty and lack of adequate knowledge therefore, school teachers and mass media have very important role in providing knowledge to adolescent girls. So efforts should be directed to impart proper knowledge to adolescents' girls to remedy this situation.

\section{Implication}

The findings of the study have implication in the field of Nursing Education, Nursing practice and Nursing research.

\subsection{Nursing Education}

Basic education of nursing and public health professional should include theory and practical aspects of education of adolescents with a special focus on teaching about nutrition and diet. Micronutrients like calcium, iron, vitamins etc. are essential for adolescent growth. Although the nursing curriculum contains the content regarding nutrition, they need to have a specific health education component with regard to nutrition and especially in the area of dietary practices and nutrition related beliefs. The school teacher should have up to date knowledge about nutrition and positive dietary practices and beliefs. All teachers training programme should include topic on guidance and counseling of adolescents related to their health in all aspects.

\subsection{Nursing Practices}

The nurses as women and components of professional have a responsibility to promote the right information and practices and beliefs among adolescent girls. School health services are an essential component of community health. The health education component with regard to nutrition, nutrition related practices and beliefs need to be strengthened during school health programs. More educational programs must be conducted in relation to nutrition. Parents should be persuaded to provide anticipatory guidance to their daughters regarding nutrition who are the future mothers and because mother's health influences the entire family. So as community health nurses play an important role in improving the nutritional status of adolescent girls.

\subsection{Nursing Research}

In India only few research studies have been conducted on nutritional status, dietary practices and beliefs of adolescent girls. These studies also reveal that there is lack of healthy practices and beliefs regarding nutrition of high school girls as compared to other aspects of health. So there is a great need for extended and intensive nursing research in the area of dietary practices and nutrition related beliefs of adolescent girls using better research methods.

\section{Conclusion}

Present study shows that majority of high school girls BMI and $\mathrm{Hb}$ level was below normal i.e. less that 18.5 (thin) and their $\mathrm{Hb}$ levels were between 10.5 and $12.49 \mathrm{gm} \%$. Nutrition related practices and beliefs revealed that some of these practices and beliefs could have affected the nutritional status of high school girls. The need for improving nutritional status and practices and beliefs is widely recognized. Therefore, it is a felt need for the bridging gap between nutritional status, dietary practices and again nutritional status and beliefs of high school girls. It is a challenge for all health personals working in the community like Community Health Nurses, School Health Nurses, and all health workers regarding nutrition and health among high school girls.

\section{References}

[1]. World Bank. Repositioning Nutrition as Central to Development: A Strategy for Large Scale Action. Washington DC: 2006. http://worldbank.org/nutrition/resources/2818461131636806329/nutritionstrategy.pdf Feb 2008.

[2]. WHO. Issues in Adolescence Health and Development. Nutrition in Adolescence - Issues and Challenges for the Health Sector; Geneva: 2005. 11-14. http://whqlibdoc.who.int/publications/2005/9241593660_eng.pdf

[3]. Taneja Priti, Bafna Rajni. Nutritional Status of tribal Adolesent Girls of Dhar District of Madhya Pradesh. The Lnd. J. Nutr. Diatet. 1997; (34): P. 314-16.

[4]. Manjula P, Barigidad, Sharada GS, Adawani Suhasini Rao, Naik Rama. Nutritional Status of Adolescent in an Urban area of Karnataka. The Indian Journal of Nutrition and Diatics. 1995: 32: 134-38. 
[5]. Kamble Rajkumar M. Nutritional Status of Adolescent girls in Western Konkan of Maharastra. The Indian Journal of Nutrition and Dietetics. 2003; (40): 416-422.

[6]. Cheethan Nicale, Klindera Kent. The Nutritional need and Status of adolescents. Internet, Washington DC USA. 2003 P1-4.

[7]. Garg B. S, Gupta Subodh S. Status of Research on Nutritional anaemia in adolescent girls. The journal of Mahatma Gandhi Institute of medical Sciences. 2000; 5(2) 39-47.

[8]. Tamang Shanta. Nutritional Assessemnt of Adolescent Refugees-Nepal, Internet. 1999:1-4.

[9]. Srivastava SP, Kumari Anjali, Bharati Lahan Kumar, Sharma Vijaya Kumar, Dietary Practices and beliefs in a adolescent girls. Indian Paediatrics 1997; Aug (34): 726-31.

[10]. Alam N, Roy SK, Ahmad T, and Shamsir A. Nutritional Status, Dietary Intake, and Relevant Knowledge of Adolescent Girls in Rural Bangladesh. Journal of Health Population and Nutrition. 2010 Feb; 28 (1): 86-94.Nutritional Status, Dietary Intake, and Relevant Knowledge of Adolescent Girls in Rural BangladeshNutritional Status, Dietary Intake, and Relevant Knowledge of Adolescent Girls in Rural Bangladesh http://www.ncbi.nlm.nih.gov/pmc/articles/PMC2975850/

[11]. Negi M, Chawla S and Sharma S. A Study on the Nutritional Status of Adolescent Girls. Plant food for Human Nutrition. 1995; 47: 201-209.

[12]. Saibaba A, Mohan Ram M, Ramana Rao GV, Devi Uma, Syamala TS. Nutritional Status of Adolescent girls of Urban Slums and the impact of IEC on their Nutritional Knowledge and Practices. Indian Journal of Community Medicine, 2002 Oct-Dec 27; (4): $151-6$.

[13]. Anand K, Kant S, Kapoor SK, Nutritional Status of adolescent school children in rural North India. Indian Paediatrics. 1999 Aug; 36: 810-14.

[14]. Gawarikar RS, Gawarikar SB. Tripathi BC. Prevalence of anaemia in adolescent girls in Ujjain in Western M.P. The Indian Journal of Nutritiona and Dieetics. 1993; (30): 66-71.

[15]. Kapil V, Bhasin s, Manocha S. Knowledge among adolescent girls about nutrition value of foods and diet during diseases pregnancy and lactation. Indian Paediatrics 1991 (28): 1135-39.

[16]. Masvi R, Sallis J F, Berry C, Broyles Shelia L, Elder John P, Nades Phillip R. The relationship between health Beliefs and Behaviours and Dietary Intake in Early Adolescence. Journal of American Dietetics Association 2002 March; 102 (3): $421-24$.

[17]. Bishnoi I, Gupta S, Gupta JNP, Traditional Beliefs and Practices Regarding Nutrition During Pregnancy. Indian Journal of Nutrition and Dietetics. 1994; (31): 11-15.

[18]. Gupta P, Bansal K. A Comparative Study of Food beliefs, Habits, and Practices in Punjabi and Jain Families. The Indian Journal of Nutrition and Dietetics 1994; 31: 16-20. 